
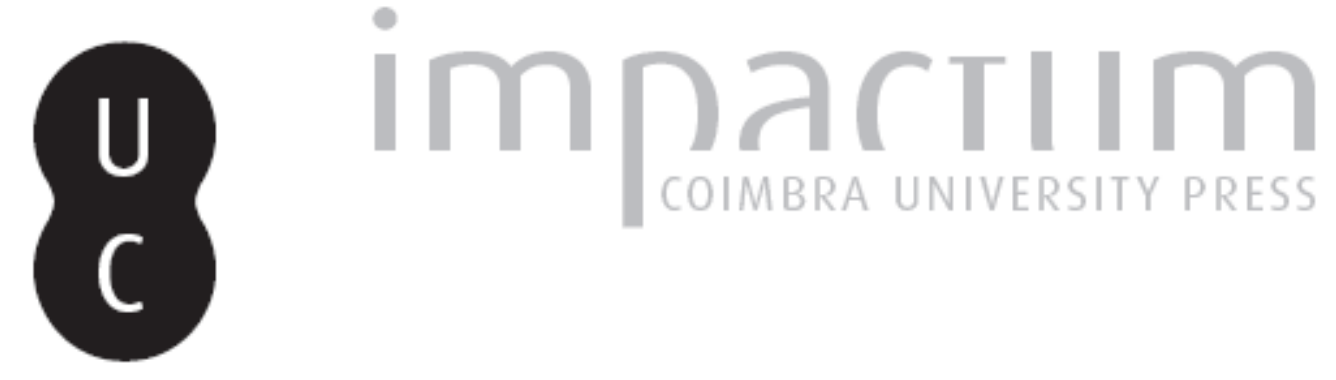

\title{
[Recensão a] Maria Marta Lobo de Araújo, Oração, penitência e trabalho. 0 Recolhimento de Santa Maria Madalena e São Gonzalo de Braga (17291834)
}

Autor(es): $\quad$ Rey Castelao, Ofelia

Publicado por: Imprensa da Universidade de Coimbra

URL persistente:

URI:http://hdl.handle.net/10316.2/43251

DOI:

DOI:https://doi.org/10.14195/0870-4147_48_15

Accessed : $\quad$ 26-Apr-2023 12:30:53

A navegação consulta e descarregamento dos títulos inseridos nas Bibliotecas Digitais UC Digitalis, UC Pombalina e UC Impactum, pressupõem a aceitação plena e sem reservas dos Termos e Condições de Uso destas Bibliotecas Digitais, disponíveis em https://digitalis.uc.pt/pt-pt/termos.

Conforme exposto nos referidos Termos e Condições de Uso, o descarregamento de títulos de acesso restrito requer uma licença válida de autorização devendo o utilizador aceder ao(s) documento(s) a partir de um endereço de IP da instituição detentora da supramencionada licença.

Ao utilizador é apenas permitido o descarregamento para uso pessoal, pelo que o emprego do(s) título(s) descarregado(s) para outro fim, designadamente comercial, carece de autorização do respetivo autor ou editor da obra.

Na medida em que todas as obras da UC Digitalis se encontram protegidas pelo Código do Direito de Autor e Direitos Conexos e demais legislação aplicável, toda a cópia, parcial ou total, deste documento, nos casos em que é legalmente admitida, deverá conter ou fazer-se acompanhar por este aviso.

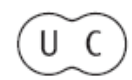




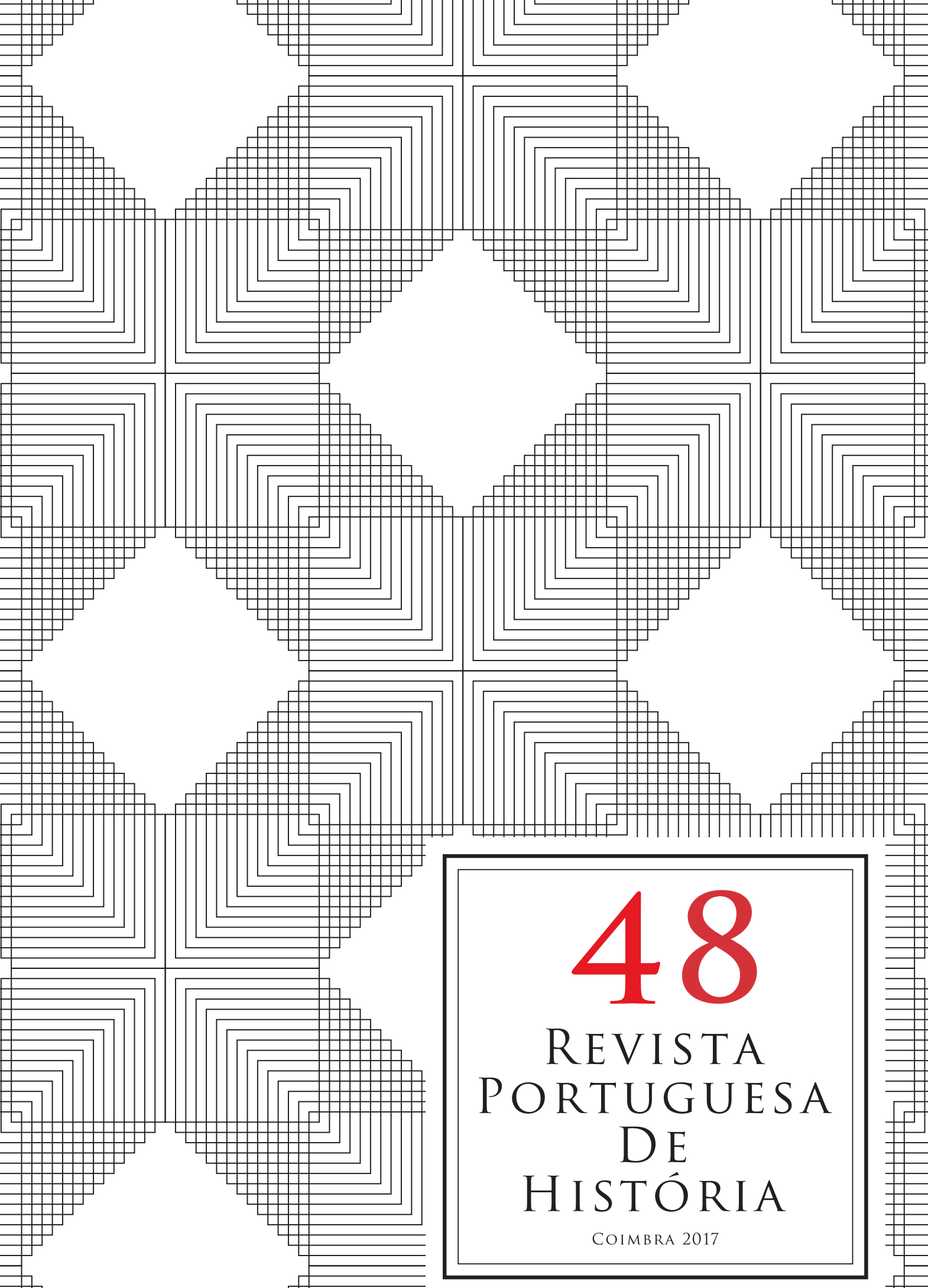


Maria Marta Lobo de Araújo, Oração, penitência e trabalho. O Recolhimento de Santa Maria Madalena e São Gonzalo de Braga (1729-1834). Famalicão, Edições Húmus, 2017, 290 p.

El sistema asistencia portugués de la Edad Moderna tenía una serie de peculiaridades que lo diferenciaban claramente del español. En algunos casos, las diferencias son más terminológicas que reales, pero en la mayoría de las instituciones y fórmulas lo son de concepción teórica y de organización práctica. Es lo que nos permite comprobar este libro que comentamos y cuya autora, María Marta Lobo, profesora en la Universidade do Minho (Braga) es bien conocida en ámbitos historiográficos hispanos porque ya ha publicado interesantes trabajos sobre este ámbito temático. En la introducción a la obra, la autora subraya las lagunas existentes todavía en el estudio del sistema asistencial portugués, pero lo cierto es que de sus citas y de la bibliografía final se deduce que Portugal cuenta ya con una bien asentada investigación, cuyo indudable interés explica los esfuerzos que últimamente se están haciendo, a pesar de que la documentación presenta serios problemas de conservación y de dispersión.

Así pues, el libro de Maria Marta Lobo es una nueva pieza en la reconstrucción de aquel sistema al estudiar una institución muy significativa, la casa de recogimiento de María Magdalena de Braga, creada en 1720 por el arzobispo don Rodrigo de Moura Teles, un prelado que sostuvo una amplia actividad de beneficencia de la que este recogimiento fue el elemento fundamental. Un recogimiento, no un convento: la autora insiste en esta aclaración, ya que popularmente - hasta hoy -, se solía llamar convento a lo que no lo era. Lo más parecido que existe en el sistema hispano serían los beaterios, con los que también los recolhimentos mantienen diferencias. La profesora Lobo expone en su introducción los problemas terminológicos derivados de ese tipo de confusiones, lo que aprovecha para identificar cada tipo institucional dedicado a la atención de mujeres. Esa misma introducción informa de las dificultades que tuvo para recomponer la documentación de la casa, debido a los avatares políticos del siglo XIX y a cambios de organización archívistica que provocaron pérdidas notables y la consiguiente desarticulación de las series. Esto da más valor a la obra, ya que se sustenta sobre un intenso trabajo de archivo y sobre una compleja hilazón de los datos hasta darles la unidad argumental que el libro tiene.

La obra se estructura en torno a seis grandes capítulos entre los cuales algunos obedecen a la tradición de estudios institucionales porque son imprescindibles. Sucede así con el primero, donde se da a conocer la fundación del recogimiento, a su fundador y a la actividad desplegada por este en la diócesis bracarense 
y su preocupación especial por la custodia de las mujeres para evitarles los peligros del siglo y "convertirlas". La entrada en la institución, sus fórmulas y los cambios en el tiempo, sirven para desarrollar los capítulos sobre el perfil social de las recogidas. Se revela así la existencia de una casa cuyas ocupantes responden a un amplio abanico de situaciones: no se trataba solo de mujeres de mala vida o mala conducta, sino solteras, que en más de un tercio de los casos eran huérfanas, otras eran jóvenes a la espera de casarse o habían huido de sus casas para evitarlo; un 17,7\% eran mujeres casadas cuyos maridos las ingresaban antes de emigrar o que se escondían de esposos maltratadotes, y el resto $(2,8 \%)$ eran viudas de variadas condiciones; es muy interesante la localización de varias mujeres emparentadas que llegaron a crear pequeñas redes de poder e influencia dentro de la casa. Unas recogidas eran pobres, otras tenían algunos bienes, unas eran urbanas, otras rurales, unas nobles y otras plebeyas: las unía la procedencia, ya que en su mayoría pertenecían al territorio diocesano, pero todo lo demás rompe con una idea estereotipada de las ocupantes de los recogimientos. Esto se explica en parte porque había dos tipos de internas, las numerarias, que no pagaban dote, y las supernumerarias; que sí la pagaban, pero lo cierto es que compartían un espacio que les daba amparo y las mantenía protegidas de una sociedad temerosa de las desviaciones de conducta protagonizadas por mujeres.

Las normas de vida de la institución, redactadas inicialmente por el arzobispo fundador en forma de estatutos que apenas cambiaron en el período estudiado, abren el segundo capítulo, en el que se describe y explica la estructura de poder, encabezada por la regente; Marta Lobo logró elaborar la serie de mujeres que ocuparon este cargo, no en vano su personalidad influía mucho en el gobierno de la casa. Estudia también el programa de conversión destinado a "dominar el cuerpo y el alma" de las recogidas, para dar paso en el capítulo siguiente a los espacios en los que se distribuía y organizaba el edificio del recogimiento - que se conserva todavía-; acoger, adoctrinar, educar, trabajar, y sobre todo vigilar, controlar y castigar, eran los objetivos que se fijaban para cada habitación; la comunicación con el exterior estaba reducida al mínimo y en todo tenía parecidos con los conventos. La autora aporta una interesante información sobre el mobiliario y sobre los elementos simbólicos que en cada espacio dejaban claro cuál era el sentido que la casa tenía y cómo eran vistas las mujeres desde la perspectiva pos-tridentina, sin asomo de los cambios que en otros aspectos se fueron produciendo en el siglo XVIII.

El soporte financiero de la institución ocupa el capítulo segundo. La casa tuvo su primera base económica en la fundación del arzobispo don Rodrigo de Moura, quien dejó establecido que sus sucesores siguieran pagando un 
tanto por recogida para asegurar su manutención. Con el paso del tiempo el recogimiento de La Magdalena recibió diferentes legados, limosnas, dotes de supernumerarias, pagos por "alimentos" de algunas de estas, y en ciertos momentos tuvo excedentes, modestos pero suficientes para poder hacer préstamos -algunos a las propias internas- que generaban intereses, de modo que la verdadera aportación de los arzobispos era del $31 \%$ a fines del siglo XVIII y los "alimentos" llegaban al 27\%. Los gastos se componían de la alimentación -un tercio del total, con el pan como elemento capital-, salarios de médico, cirujano, sangrador y otros oficiales, de actos litúrgicos y fiestas religiosas, y otros típicos de este tipo de instituciones.

$\mathrm{Al}$ inicio del libro, la autora expone su interés en la existencia cotidiana dentro del recogimiento y, en efecto, una extensa parte se dedica a la vida comunitaria en dos facetas, el alimento del cuerpo y el del espíritu. Lo primero se analiza en el capítulo quinto, vinculando las prácticas alimentarias -sus componentes básicos diarios, los extraordinarios impuestos por el calendario litúrgico o arreglados a las fiestas- con las prácticas del refectorio, incluida la lectura en voz alta, para lo que había una pequeña biblioteca. Lo otro se observa desde dos ángulos, el de la fiesta y el de la conflictividad interna; este aspecto tiene un especial interés, ya que revela las tensiones que se producían en la clausura a la que las mujeres estaban sometidas y que en algunas ocasiones produjeron huidas de las internas, y en otras, expedientes de expulsión. Estos expedientes y otras soluciones duras se tomaron después de momentos de especial virulencia, como los vividos en 1743, 1759 o 1816, en los que fue precisa la intervención de los prelados para poner orden. Eran conflictos y luchas de poder entre mujeres, muchas de ellas de edad avanzada que llevaban largo tiempo encerradas.

El capítulo final continúa la observación de lo cotidiano del recogimiento de María Magdalena, pero incide en la limpieza y en el abastecimiento de agua para mantener la higiene de las internas, en su asistencia en caso de enfermedad, y sobre todo en la muerte dentro de la clausura. Este aspecto se fundamenta en los estatutos pero también en los testamentos de las recogidas que la autora pudo reunir, lo que le permite ver el tipo de mortaja que preferían -el de la Orden Tercera Franciscana-, el acompañamiento en las ceremonias fúnebres -familia, sacerdotes, cofradías-, los actos litúrgicos posteriores, así como el escenario donde transcurrían, la capilla del centro. Es importante señalar que el recogimiento tenía su vida diaria regida por la regla de la mencionada Orden Tercera, pero en 1755 pasó a regirse por la de la Congregación del Sagrado Corazón de Jesús - instituida por el jesuita español Pedro de Calatayud cuando visitó Braga en 1743 -, y así continuó hasta el final. 
El libro concluye con la transcripción de los estatutos antiguos de la institución y con una extensa y actualizada bibliografía, que nos permite localizar las más recientes aportaciones de la bibliografía portuguesa. A lo largo del libro, la autora revela su interés en comparar el caso estudiado con otros, para subrayar su carácter y para ponerlo en el contexto católico postridentino de tratamiento dado a las mujeres que por su soledad, su pobreza o su comportamiento generaban temores a la sociedad -orientada por el clero-y el tratamiento dado a esos temores, basado en el encierro para lograr su "conversión". Sin embargo, el encierro terminó siendo un modo de vida al que se acogieron voluntariamente otras mujeres, aquellas que buscaban protección temporal o, en un gran número de casos, definitiva. El estudio de Marta Lobo, reconstruye de forma clara y fundamentada esa dimensión social del recogimiento de María Magdalena durante un largo siglo en el que fuera de los muros de la casa, la sociedad bracarense iba cambiando, contribuyendo a la historia de las mujeres del Portugal moderno.

Ofelia Rey Castelao

Universidad de Santiago de Compostela ofelia.rey@usc.es 